\title{
An approach of controlling the inverter-based generator for use in an islanded microgrid
}

\author{
Suchart Janjornmanit, Sakorn Panta, Vishnu Thonglek \\ Department of. Electrical Engineering, Rajamangala University of Technology Lanna, Thailand
}

\begin{tabular}{l} 
Article Info \\
\hline Article history: \\
Received Jan 18, 2020 \\
Revised Apr 22, 2020 \\
Accepted May 5, 2020 \\
\hline
\end{tabular}

Keywords:

Active power control

Angle control

Microgrid

Power generation control

Reactive power control

\begin{abstract}
The controls of power generation by the inverter-based generator are proposed in this work. The proposed control adjusts the active power output by varying the phase angle instead of the conventional frequency variation. The benefit of operating the network by a fixed frequency is that it eradicates the problems associated with the frequency deviation. The PID controls with recommended gain adjustment are proposed to control the power generation. The power generation schemes are adapted from the classical power generation by the synchronous generator, where the modes of operation are Swing, PV and PQ mode. The proposed three modes of operation are adequate to operate fully in a small-scale power system such as in an islanded microgrid. A case study of operating the proposed controls in a microgrid by simulation is used to demonstrate the feasibility of implementation of the controls.
\end{abstract}

This is an open access article under the CC BY-SA license.

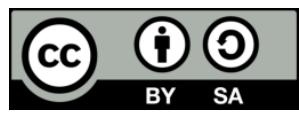

\section{Corresponding Author:}

Suchart Janjornmanit,

Department of Electrical Engineering,

Rajamangala University of Technology Lanna,

128 Huay Kaew Road, A. Mueng, Chiang Mai, Thailand.

Email: suchart@ rmutl.ac.th

\section{INTRODUCTION}

The microgrid concept is gaining attention in power system engineer communities nowadays. The need to separate the power system into a microgrid in some area is growing. It has been forecast that the capacity of the microgrid will increase to six times of today's capacity in the next decade [1]. Its operation and control are still in the developing stage and remain challenging. The main resource of power supply in the microgrid is renewable energy [2]. The growing concern over climate change which is majorly caused by overconsumption of fossil fuel is driving the trend of moving toward renewable sources. Many countries, such as those in Europe are reducing their carbon footprints by welcoming renewable sources. A challenge for power system engineers is interconnecting power generation by conventional fossil fuel generators and renewable sources. The power generated by the conventional hydro and fossil source is mostly delivered by the synchronous generator. Meanwhile, the renewable source converts energy to the network by the inverterbased generator. A main feature of power generation by the synchronous generator is that the active power output is varied by adjusting the output voltage frequency. This relationship is manipulated to use in the control of power generation in the microgrid, called "droop control", such as in [3-8]. Applications of droop control can be found in recent publications such as in [9-15]. Droop-based control has gained popularity due to its simplicity and autonomous operation. However, this imitation of the operation of the synchronous generator is somewhat problematic. Without using properly chosen droop gain coefficients, the system can become unstable $[8,16-19]$. Due to its drawback, the synthesis of droop will be eliminated in the proposed control. It has also been reported that droop control does not work properly with resistive line [19-21]. There 
is no problem related to the resistive line for the proposed control. In addition, the fallout of frequency deviation, such as the frequency stability, is considered a critical issue for the secure microgrid operation. The frequency deviation will be eliminated in the proposed controls. There are works that attempt to adjust the phase angle instead of frequency [22-24]. These works use the angle droop to control the power sharing in the microgrid. The controls need a GPS to synchronize the operation, which is not reliable. While active power generation is also controlled by adjusting the phase angle in the proposed control, it needs no droop equation and GPS system to control the phase angle adjustment. The work in [25] avoids using droop control completely by application of instantaneous power theory, to approximate the line impedance. However, the approximation cannot guarantee the performance of the power generation. There is no need to use the line impedance value or its approximation to formulate the proposed control.

In this work, PID control scheme is used to control the power generation by phase angle adjustment. The proposed PID control is divided into subsets of power generation that mimics the power generation using synchronous generator. Three modes of operation, Swing; PV and PQ mode, are introduced to control the inverter-based generator. These control subsets are suitable to form the full control of a power system network. PID gain selection is also recommended in every control subset.

This paper is organized into the following sections. First, the proposed PID controls and the modes of operation are detailed. Second, in order to prove the feasibility of its implementation in the real power system, a case study of a microgrid is demonstrated by simulation. Lastly, this research is summarized in the conclusion section.

\section{THE PROPOSED CONTROL}

In Figure 1, the proposed control of power generation is a kind of Voltage Source Inverter (VSI) that generates power flowing through the output inductor $L_{g}$. The inductor is a crucial part of controlling output power in this work. It filters out the discontinuities of phase change due to the adjustment of the proposed control. In addition, its sizing affects both of the power generation capacity and the PID gain adjustment. The proposed control is the reference voltage generator of the VSI, it generates the voltage reference $\left|V_{g}{ }^{*}\right| \angle \delta_{g}{ }^{*}$ for the voltage controller of the inverter as depicted in Figure 2. PID control is used to generate the reference voltage in this work. The magnitude and phase of the reference voltage are fixed from the start to the end of the voltage cycle, and are updated periodically every 1-5 cycles. The differences in magnitude and phase of the generating voltage $V_{g}$ and terminal voltage $V_{t}$ are used to control the reactive and active power generation respectively. In this paper, three kinds of Distributed Generator (DG) which are sufficient for fully operating in a microgrid, are proposed. The proposed DGs are VSIs that operate in three modes of power generation, mimic the modes of operation of the synchronous generator. The proposed three modes of operation are 1) Swing control, 2) PV control and 3) PQ control. The detail of each mode is proposed in the following subsections.

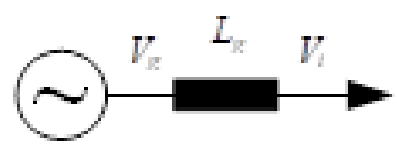

Figure 1. The proposed control of power generation

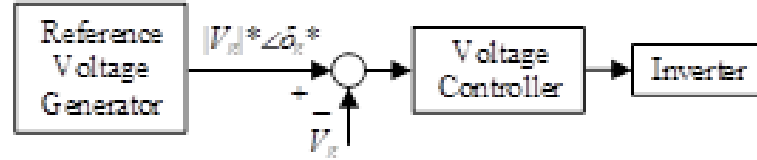

Figure 2. The reference voltage generator

\subsection{Swing control mode}

In this mode, the active and reactive power generation are not specified. The magnitude and phase angle of the terminal voltage are controlled to be fixed values. The proposed reference voltage generator of this mode is shown in Figure 3. The control of the magnitude of terminal voltage is a PI control. The proportional and integral gain for the control found to provide satisfactory performance are

$$
K_{p}=K_{i}=1
$$

The control of the phase angle of terminal voltage $\delta_{t}$ is also a PI control. The phase angle of generating voltage $\delta_{g}$ is adjusted by adding the controlled phase angle difference $\Delta \delta$ to the detected phase angle of the voltage at the terminal $\delta_{t}$. The proportional and integral gain for the phase angle control found to provide satisfactory performance are also in (1). 


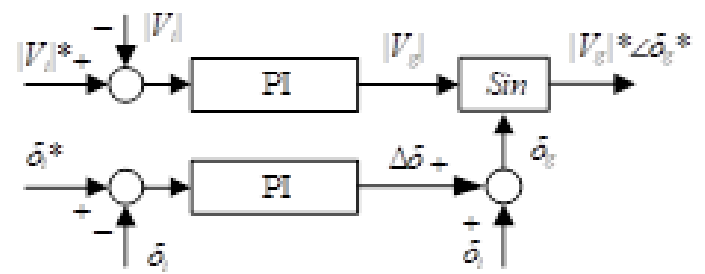

Figure 3. The swing control mode.

\subsection{PV control mode}

In this mode, the active power generation is specified, whereas the reactive power is not. In addition, the magnitude of terminal voltage is also specified. The proposed reference voltage generator of this mode is shown in Figure 4. The control of the magnitude of terminal voltage in this mode is also the same as the PI control in the proposed swing control mode. The proportional and integral gain for the control found to provide satisfactory performance are also in (1)

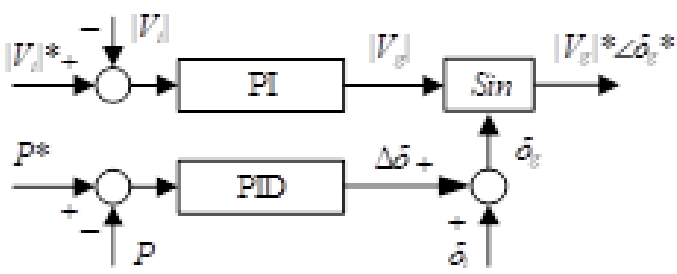

Figure 4. The PV control mode

The control of the active power generation $P$ is a PID control. It is used to adjust the phase angle difference $\Delta \delta$ between terminal and generating voltage. The phase angle of the generating voltage $\delta_{g}$ is calculated by adding the controlled phase angle difference $\Delta \delta$ to the detected phase angle of the voltage at the terminal $\delta_{t}$. The proportional gain $K_{p}$ for the PID control of the phase angle difference found to provide satisfactory performance, can be calculated by

$$
K_{p}=0.1 \frac{X_{g}}{\left(\left|V_{b u s}\right| *\right)^{2}}
$$

where $X_{g}$ is the inductance of the output inductor and $\left|V_{b u s}\right|^{*}$ is a rated voltage magnitude at the connected bus. The integral and derivative gain of the PID control are

$$
K_{i}=2 K_{p}
$$

and

$$
K_{d}=0.1 K_{p}
$$

respectively.

\subsection{PQ control mode}

In this mode, both active and reactive power generation are specified. The proposed reference voltage generator of this mode is shown in Figure 5. The control of active power generation in this mode is also the same as the PID control in the previous PV control mode. The PID gain for the control found to provide satisfactory performance can be calculated in the same manner as (2)-(4). 


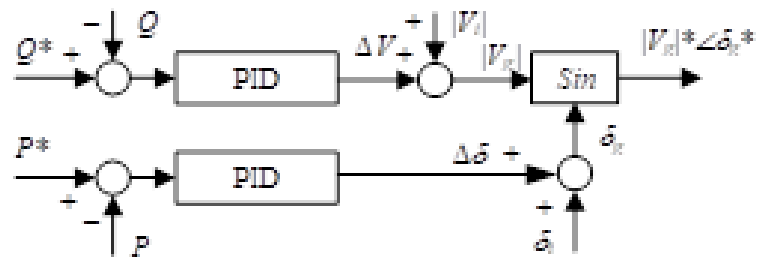

Figure 5. The PQ control mode.

The control of the reactive power generation $Q$ is a PID control. It is used to adjust the voltage magnitude difference $\Delta V$ between terminal and generating voltage. The magnitude of generating voltage $\left|V_{g}\right|$ is calculated by adding the controlled magnitude difference $\Delta V$ to the detected magnitude of the voltage at the terminal $\left|V_{t}\right|$. The proportional gain $K_{p}$ for the PID control of the magnitude difference found to provide satisfactory performance can be calculated by

$$
K_{p}=0.1 \frac{X_{g}}{\left|V_{\text {bus }}\right|^{*}}
$$

The integral and derivative gain of the PID control are

$$
K_{i}=2 K_{p}
$$

and

$$
K_{d}=0.1 K_{p}
$$

respectively.

\section{SIMULATION STUDY, RESULTS AND DISCUSSION}

A case study of meshed network is used to demonstrate the feasibility of implementation of the proposed controls by means of MATLAB/SIMULINK simulation. The simulation is performed on a personal notebook computer with i7 core chipset. A fixed-step type with discrete solver is used in the simulation. With the fixed-step size of 2 microseconds, the solver takes roughly 5 minutes to complete a task of simulation time shorter than 5 seconds. Figure 6 shows the configuration of the demonstrated power system, which can be regarded as an islanded microgrid. The network is a three phase $380 \mathrm{~V} / 50 \mathrm{~Hz}$. It consists of 5 buses with three DGs connected to three buses and the other two buses are load buses. The three DGs operate in Swing control mode for bus no.1, PV control mode for bus no.3 and PQ control mode for bus no.5. The lines connecting between buses are the combination of both resistive and inductive line types. The specification of power generation, load and voltage of each bus are shown in Table 1. The simulation results of the system that is operated to the point that the system is in stable and steady state condition, are in Table 2-4. Per unit values are shown in all figures and tables are calculated by base $\mathrm{kV}_{\mathrm{LL}}=0.38$ and base $\mathrm{MVA}=1$.

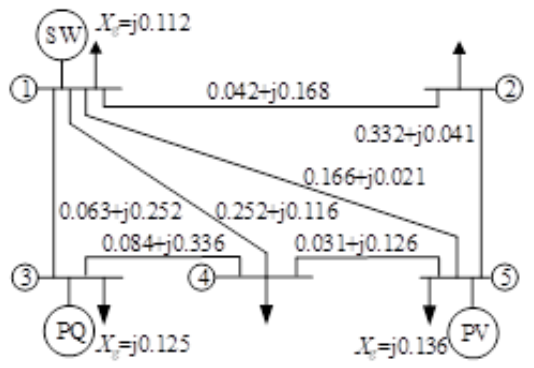

Figure 6. The configuration of the demonstrated microgrid. 
Table 1. Specification of generators and loads.

\begin{tabular}{cccccccc}
\hline \multirow{2}{*}{ Bus } & \multicolumn{2}{c}{ Generation } & \multicolumn{2}{c}{ Load } & \multicolumn{2}{c}{ Voltage $\left(V_{t}\right)$} & \multirow{2}{*}{ Bus type } \\
& $\mathrm{P}(\mathrm{pu})$ & $\mathrm{Q}(\mathrm{pu})$ & $\mathrm{P}(\mathrm{pu})$ & $\mathrm{Q}(\mathrm{pu})$ & $\mathrm{pu}$ & Angle & \\
\hline 1 & no & no & 0.75 & 0.4 & 1.03 & 0 & Swing \\
2 & $\ldots$. & $\ldots$. & 1.25 & 0.5 & no & no & Load \\
3 & 1.75 & 1 & 0.6 & 0.3 & no & no & PQ \\
4 & $\ldots$. & $\ldots$. & 0.9 & 0.5 & no & no & Load \\
5 & 1 & no & 0.55 & 0.3 & 1.02 & no & PV \\
\hline
\end{tabular}

The simulation results of power that are generated and supplied to the loads of buses are in Table 2 and the results of power flow between buses are in Table 3. It can be seen in Table 2 that the proposed PV and PQ mode DGs are able to generate the power to the specified values, $P=1 \mathrm{pu}$ of $\mathrm{PV}, P=1.75 \mathrm{pu}$ and $Q=1 \mathrm{pu}$ of PQ. The powers supplied to the loads do not exactly match their specification. This is because the voltage at its connected bus deviates slightly from the rated voltage, which is a normal operation.

Table 2. Results of power

\begin{tabular}{cccccc}
\hline \multirow{2}{*}{ Bus } & $\mathrm{P}(\mathrm{pu})$ & $\mathrm{C}$ & \multicolumn{2}{c}{ Load } & \multicolumn{2}{c}{ Remark } \\
\hline 1 & $1.45\left(\Delta \delta=2.47^{\circ}\right)$ & $0.95(\Delta V=0.0455 \mathrm{pu})$ & 0.79 & 0.42 & Swing Bus \\
2 & $\ldots$ & $\ldots$. & 1.19 & 0.48 & Load Bus \\
3 & $1.75\left(\right.$ controlled, $\left.\Delta \delta=3.19^{\circ}\right)$ & 1 (controlled. $\Delta V=0.0524 \mathrm{pu})$ & 0.67 & 0.33 & PQ Bus \\
4 & $\ldots .$. & $\ldots$ & 0.91 & 0.51 & Load Bus \\
5 & 1 (controlled, $\left.\Delta \delta=2.39^{\circ}\right)$ & $0.24(\Delta V=0.0184 \mathrm{pu})$ & 0.56 & 0.31 & PV Bus \\
\hline$*$ Result of system frequency is $50.00 \mathrm{~Hz}$ & & & &
\end{tabular}

Table 3. Results of power flow between buses

\begin{tabular}{ccc}
\hline Line & $\mathrm{P}(\mathrm{pu})$ & $\mathrm{Q}(\mathrm{pu})$ \\
\hline Bus no.1 to Bus no.2 & 0.81 & 0.78 \\
Bus no.1 to Bus no.3 & -0.55 & -0.29 \\
Bus no.1 to Bus no.4 & 0.23 & 0.01 \\
Bus no.1 to Bus no.5 & 0.18 & -0.01 \\
Bus no.2 to Bus no.5 & -0.41 & 0.24 \\
Bus no.3 to Bus no.4 & 0.52 & 0.37 \\
Bus no.4 to Bus no.5 & -0.18 & -0.17 \\
\hline
\end{tabular}

*Result of system frequency is $50.00 \mathrm{~Hz}$

The simulation of voltages at buses and the generated voltages of DGs are in Table 4. It can be seen that the proposed Swing control mode DG is able to generate the terminal voltage to the specified magnitude of $1.03 \mathrm{pu}$ while maintaining its phase reference of $0^{\circ}$. In addition, the proposed PV control mode DG is simultaneously able to generate the terminal voltage to its specified magnitude of $1.02 \mathrm{pu}$.

Table 4. Results of voltages

\begin{tabular}{cccccc}
\hline \multirow{2}{*}{ Bus } & \multicolumn{6}{c}{$V_{g}$} & \multicolumn{2}{c}{$V_{\text {bus }}$} & Bus type \\
& pu. & Angle & pu. & Angle & \\
\hline 1 & 1.0755 & $2.47^{\circ}$ & 1.03 (controlled) & $0^{\circ}$ (controlled) & Swing Bus \\
2 & $\ldots$ & $\ldots$. & 0.9771 & $-1.93^{\circ}$ & Load Bus \\
3 & 1.1155 & $5.31^{\circ}$ & 1.0631 & $2.12^{\circ}$ & PQ Bus \\
4 & $\ldots$. & $\ldots \ldots$ & 1.0111 & $-0.42^{\circ}$ & Load Bus \\
5 & 1.0384 & $2.31^{\circ}$ & 1.02 (controlled) & $-0.08^{\circ}$ & PV Bus \\
\hline * Result of system frequency is $50.00 \mathrm{~Hz}$ &
\end{tabular}

It can be seen that the voltage magnitude in some points of the network is greater than $5 \%$ of the rated voltage. This is due to the fact that the overall reactive power in this network is relatively high. Therefore, these create the condition that the DGs needed to raise its output voltage to adequately supply reactive power. In practice, the reactive power demand can be supplied by the capacitor bank then voltages in the network should be lower.

The angle deviation can be evaluated from the results of voltages in Table 4. It can be seen that all buses have their own voltage angle. In the proposed controls, the real and reactive power, the voltage 
magnitude and angle, are controlled depending on mode of operation. P and Q are generated independently by adjusting the differences of voltage angle and magnitude respectively. The difference is controlled locally to the connected bus, the proposed control uses the voltage angle and magnitude at the connected bus as the information to communicate between controls.

In order to prove its dynamic response, the same system is simulated continually by changing the command of active and reactive power of the PQ mode DG. At the time of second 2, the reference P and Q of DG3 were changed from $1.75 \mathrm{pu}$ and $1 \mathrm{pu}$, to $2 \mathrm{pu}$ and $0.8 \mathrm{pu}$ respectively. It can be seen from Figure 7 that both P and Q of DG3 are able to change to the new setpoints. Where P and V of DG5, in addition to the magnitude and phase angle of voltage at the Swing bus, are able to maintain their set points after the changing. In Figure $7 \mathrm{~d}$ ), the system frequency fluctuates very little due to the adjustment of the voltage angle by the controls, and returns to $50.00 \mathrm{~Hz}$ very quickly.

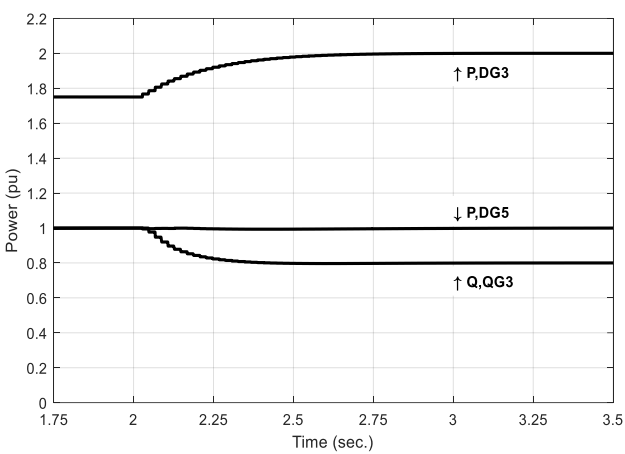

(a)

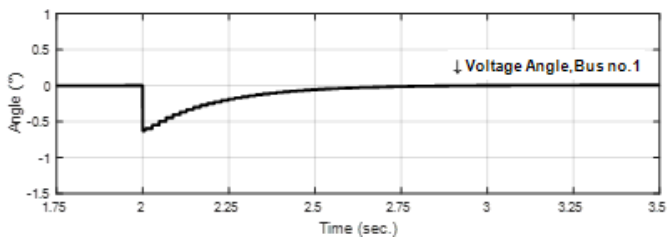

(c)

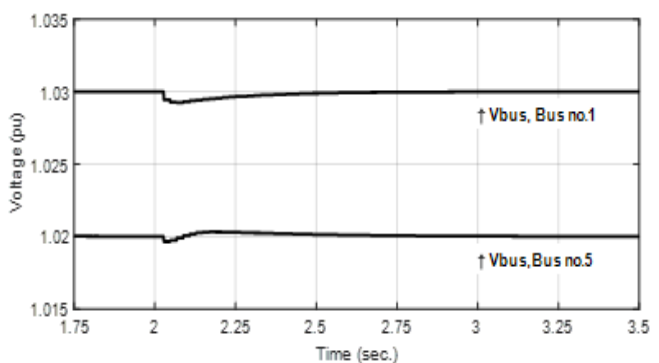

(b)

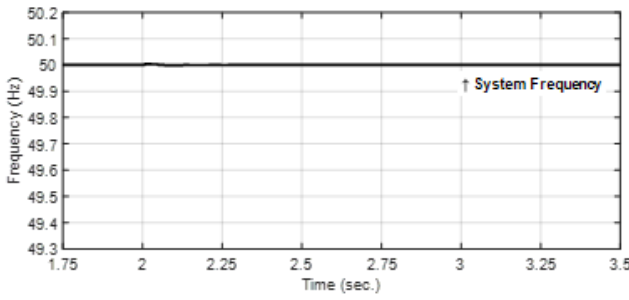

(d)

Figure 7. The results of controlled values after changing, a) power, b) voltage, c) angle and d) system frequency.

\section{CONCLUSION}

The control of power generation in a microgrid that eliminates the frequency stability's problem is proposed in this work. Unlike the conventional active power generated by varying frequency, the proposed control is achieved by varying the phase angle. The PID control with recommended gain adjustment, is used to control to mimic the modes of operation of the synchronous generator. This transforms the classical control operation of the synchronous generator in the main power grid into a small-scale power system using the inverter. With fixed system's frequency, the control of power generation is much smoother than its droop control counterpart. The simulation results prove its feasibility that this type of controls can be implemented in a real microgrid by using voltage source inverters. The power generated by the proposed inverter is the power generation of the future because of the growing trend of moving toward renewable energy.

\section{REFERENCES}

[1] A. Mohammed, S. S. Refaat, S. Bayhan and H. Abu-Rub, "AC Microgrid Control and Management Strategies: Evaluation and Review," IEEE Power Electronics Magazine, vol. 6, no. 2, pp. 18-31, 2019.

[2] B. Kroposki et al., "Achieving a 100\% Renewable Grid: Operating Electric Power Systems with Extremely High Levels of Variable Renewable Energy," IEEE Power and Energy Magazine, vol. 15, no. 2, pp. 61-73, 2017.

[3] J. Rocabert, A. Luna, F. Blaabjerg and P. Rodríguez, "Control of Power Converters in AC Microgrids," IEEE Transactions on Power Electronics, vol. 27, no. 11, pp. 4734-4749, 2012. 
[4] J. M. Guerrero, M. Chandorkar, T. Lee and P. C. Loh, "Advanced Control Architectures for Intelligent Microgrids-Part I: Decentralized and Hierarchical Control," IEEE Transactions on Industrial Electronics, vol. 60, no. 4, pp. 1254-1262, 2013.

[5] M. Ashabani, Y.A.-R.I. Mohamed, M. Mirsalim and M. Aghashabani, "Multivariable Droop Control of Synchronous Current Converters in Weak Grids/Microgrids With Decoupled dq-Axes Currents," IEEE Trans. Smart Grid, Vol. 6, No. 4, pp. 1610-1620, 2015.

[6] W. Ferreira de Souza, M.A. Severo-Mendes and L.A.C. Lopes, "Power sharing control strategies for a three-phase microgrid in different operating condition with droop control and damping factor investigation," IET Renewable Power Gener., Vol. 9, No. 7 pp. 831-839, 2015.

[7] M.S. Golsorkhi and D.D.C. Lu, "A Control Method for Inverter-Based Islanded Microgrids Based on V-I Droop Characteristics," IEEE Trans. Power Delivery, Vol. 30, No. 3, pp. 1196-1204, 2015.

[8] U. Akram, R. Shah and N. Mithulananthan, "Hybrid energy stoarage system for frequency regulation in microgrids with source and load uncertainties," IET Generation, Transmission \& Distribution, vol. 13, no. 22, pp. 5048-5057, 2019.

[9] A. Firdaus and S. Mishra, "Auxiliary signal-assisted droop-based secondary frequency control of inverter-based PV microgrids for improvement in power sharing and system stability," IET Renewable Power Generation, vol. 13, no. 13 , pp. 2328-2337, 2019.

[10] H. Moon, Y. Kim and S. Moon, "Frequency-Based Decentralized Conservation Voltage Reduction Incorporated into Voltage-Current Droop Control for an Inverter-Based Islanded Microgrid," IEEE Access, vol. 7, pp. 140542-140552, 2019.

[11] S. Roozbehani, M. T. Hagh and S. G. Zadeh, "Frequency control of islanded wind-powered microgrid based on coordinated robust dynamic droop power sharing," IET Generation, Transmission \& Distribution, vol. 13, no. 21, pp. 4968-4977, 2019.

[12] A. Kumar, B. K. Jha, D. Singh and R. K. Misra, "Current injection-based Newton-Raphson power-flow algorithm for droop-based islanded microgrids," IET Generation, Transmission \& Distribution, vol. 13, no. 23, pp. 5271-5283, 2019.

[13] A. Uniyal and S. Sarangi, "Optimal allocation of ELC in microgrid using droop-controlled load flow," IET Generation, Transmission \& Distribution, vol. 13, no. 20, pp. 4566-4578, 2019.

[14] F. Feng and P. Zhang, "Enhanced Microgrid Power Flow Incorporating Hierarchical Control," IEEE Transactions on Power Systems, vol. 35, no. 3, pp. 2463-2466, 2020.

[15] E. Espina, R. Cárdenas-Dobson, M. Espinoza-B., C. Burgos-Mellado and D. Sáez, "Cooperative Regulation of Imbalances in Three-Phase Four-Wire Microgrids Using Single-Phase Droop Control and Secondary Control Algorithms," IEEE Transactions on Power Electronics, vol. 35, no. 2, pp. 1978-1992, 2020.

[16] B. K. Unnikrishnan, M. S. Johnson and E. P. Cheriyan, "Small signal stability improvement of a microgrid by the optimised dynamic droop control method," IET Renewable Power Generation, vol. 14, no. 5, pp. 822-833, 2020.

[17] R. Majumder, B. Chaudhuri, A. Ghosh, R. Majumder, G. Ledwich and F. Zare, "Improvement of stability and load sharing in an autonomous microgrid using supplementary droop control loop," IEEE PES General Meeting, Providence, RI, pp. 1-1, 2010.

[18] Z. Shi, J. Li, H. I. Nurdin and J. E. Fletcher, "Transient response comparison of virtual oscillator controlled and droop controlled three-phase inverters under load changes," IET Generation, Transmission \& Distribution, vol. 14, no. 6, pp. 1138-1147, 2020 .

[19] G. Raman and J. C. Peng, "Mitigating Stability Issues Due to Line Dynamics in Droop-Controlled Multi-Inverter Systems," IEEE Transactions on Power Systems, vol. 35, no. 3, pp. 2082-2092, 2020.

[20] S. Tabatabaee, H. R. Karshenas, A. Bakhshai and P. Jain, "Investigation of droop characteristics and X/R ratio on small-signal stability of autonomous Microgrid," 2011 2nd Power Electronics, Drive Systems and Technologies Conference, Tehran, pp. 223-228, 2011.

[21] W. Yao, M. Chen, J. Matas, J. M. Guerrero and Z. Qian, "Design and Analysis of the Droop Control Method for Parallel Inverters Considering the Impact of the Complex Impedance on the Power Sharing," IEEE Transactions on Industrial Electronics, vol. 58, no. 2, pp. 576-588, 2011.

[22] R. Majumder, A. Ghosh, G. Ledwich and F. Zare, "Angle droop versus frequency droop in a voltage source converter based autonomous microgrid," 2009 IEEE Power \& Energy Society General Meeting, Calgary, AB, pp. 1-8, 2009.

[23] B. John, A. Ghosh and F. Zare, "Load Sharing in Medium Voltage Islanded Microgrids With Advanced Angle Droop Control," IEEE Transactions on Smart Grid, vol. 9, no. 6, pp. 6461-6469, 2018.

[24] H. Moussa, A. Shahin, J. Martin, S. Pierfederici and N. Moubayed, "Optimal Angle Droop for Power Sharing Enhancement with Stability Improvement in Islanded Microgrids," IEEE Transactions on Smart Grid, vol. 9, no. 5, pp. 5014-5026, 2018

[25] A. Ovalle, G. Ramos, S. Bacha, A. Hably and A. Rumeau, "Decentralized Control of Voltage Source Converters in Microgrids Based on the Application of Instantaneous Power Theory," IEEE Trans. Ind. Electron., Vol. 62, No. 2 , pp. 1152-1162, 2015 